\title{
Participación de los estados soberanos en el ramo general de bienes de manos muertas en la segunda mitad del siglo XIX colombiano
}

\author{
por \\ Maribel De la Cruz-Vergara1 \\ Universidad de Cartagena, Colombia
}

El objetivo de esta investigación gira en torno al análisis cuantitativo de la participación de los Estados Soberanos, en el ramo general de bienes de manos muertas en la segunda mitad del siglo XIX colombiano, a través de la interpretación de los informes de los agentes generales de bienes desamortizados y los datos reportados en las memorias de la hacienda pública.

Palabras Clave: Colombia; desamortización; Estados Soberanos; bienes; remates.

Cómo Citar este artículo / Citation: De la Cruz-Vergara, Maribel, "Participación de los estados soberanos en el ramo general de bienes de manos muertas en la segunda mitad del siglo XIX colombiano", Revista de Indias, LXXVIII/272 (Madrid, 2018): 175-210. https://doi. org/10.3989/revindias.2018.006

\section{INTRODUCCIÓN}

En Colombia ${ }^{2}$, la segunda mitad del siglo XIX se caracterizó por una serie de reformas económicas, políticas e institucionales que venían gestándose

1 mdelacruzv@unicartagena.edu.co, ORCID iD: https://orcid.org/0000-0002-5814-757X.

2 El actual territorio colombiano - de acuerdo con los marcos constitucionales, las formas de gobierno y los conflictos entre los partidos políticos en el siglo XIX-, recibió varios nombres: República de Colombia (1821-1832), Estado de la Nueva Granada (1832-1843), República de la Nueva Granada (1843-1858), Confederación Granadina (1858-1863) y Estados Unidos de Colombia (1863-1886). La última Constitución del siglo XIX fue la de 1886 que, después de múltiples actos legislativos que la modificaron, fue derogada en 1991. En la actual 
desde tiempo atrás; en el período comprendido entre 1850 y 1886 es cuando dichas reformas encuentran las condiciones propicias para establecerse, sobre todo las relacionadas con la definición de la forma de la propiedad sobre la tierra en función de su rentabilidad y aquellas que tienen que ver con los bienes muebles e inmuebles y semovientes articulados con el censo eclesiástico. Las discusiones surgidas en este contexto intentaban legitimar y llevar a la práctica el concepto de propiedad privada sobre la tierra, la libertad individual y la protección de los bienes de los ciudadanos, los cuales estaban presente en todas las constituciones republicanas, pero que se habían convertido en el problema por resolver durante los gobiernos liberales radicales de Mosquera, Murillo y Santos 3 .

Entre este conjunto de reformas una de las más importantes fue la relacionada con la propiedad de la tierra, llevada a cabo a través de la enajenación de tierras baldías, la desamortización de bienes de manos muertas, la expropiación de ejidos municipales y la individualización de las tierras de resguardos indígenas. La desamortización de bienes de manos muertas, objeto de esta investigación, se convirtió en uno de los temas más polémicos de finales de dicho siglo, ya que representó, además de un problema ideológico, la legitimación y puesta en práctica del concepto de propiedad individual sobre la tierra.

Entenderemos la desamortización como un proceso jurídico político instaurado por la monarquía española y retomado en la república, con el fin de poner en el mercado los bienes amortizados por la Iglesia y bienes afectos a esta; para modernizar las estructuras sobre la propiedad, la forma de adquisición de los bienes y pagar la deuda pública. La desamortización hizo alusión a los siguientes procesos: la desamortización sobre bienes eclesiásticos, la desamortización sobre bienes comunales o municipales y la desamortización

Constitución, promulgada en 1991, aún se conserva el nombre de República de Colombia. De la Cruz-Vergara, 2014a: 31-65.

3 El general Mosquera llevó a la práctica, a través de la desamortización de bienes de manos muertas, una preocupación que ocupaba a los gobernantes desde la segunda mitad del siglo XVIII, como fue la inmovilidad de la tierra por encontrarse ésta bajo la figura de manos muertas. Sin embargo, el auge de dicha reforma no se dio únicamente durante su mandato, sino, también, durante las presidencias de Manuel Murillo Toro (1864-1866, 1872-1874), quien se mostró proclive al diálogo con la Iglesia, aunque en lo que tenía que ver con la reforma a la tierra siguió ejecutando los preceptos constitucionales; es decir, el fortalecimiento de la propiedad privada y, por tanto, la necesidad de desarticular los bienes de manos muertas. José María Rojas Garrido (1866), Joaquín Riascos (1867) y Santos Acosta (1867-1868), gobernantes provenientes de diferentes sectores del liberalismo, estuvieron en contraposición a las aspiraciones mismas de Mosquera. 
sobre bienes civiles. La amortización se refiere al estancamiento de la tierra desde el punto de vista de la libre circulación, es decir, es el paso de la tierra a manos muertas ${ }^{4}$. La amortización, fundamentalmente, era de dos clases: la amortización civil y la amortización eclesiástica. La amortización civil se define como la separación de ciertos bienes de la circulación o libre comercio a favor de algunas instituciones civiles de establecimiento público tales como fideicomiso, mayorazgos, patronatos, memorias pías, entre otros. La amortización eclesiástica se define como la adquisición hecha por la Iglesia, monasterios o comunidades de bienes de cualquier clase.

Al igual que en América Latina, en Colombia ${ }^{5}$, las investigaciones referidas a este tema son escasas; sin embargo, se ha avanzado en estudios regionales y nacionales ${ }^{6}$, en donde se han planteado marcos conceptuales a la luz de las políticas liberales ${ }^{7}$ e introducido análisis cuantitativos para abordar dicho proceso. Por tanto, con el fin de seguir ahondando en el tema, en esta investigación profundizaremos sobre la participación de los Estados Soberanos en la desamortización de los bienes de manos muertas ${ }^{8}$, proponiendo como hipótesis central que esta fue una política nacional manifestada en su estructura administrativa y contable, así como en la articulación misma de los Estados Soberanos con el ramo general de bienes desamortizados.

Para ello, analizaremos las cuentas de inscripción, avalúo y remates de este ramo en un período de 14 años y su articulación con las agencias subalternas ubicadas en cada uno de los Estados. La idea, entonces, es presentar los mecanismos, la recaudación de bienes en cada uno de estos y los remates realizados, finalizando con un balance general sobre las cuentas de la agencia general de bienes desamortizados. Para lograr tal cometido, esta cuestión la abordaremos a partir de tres ejes temáticos: uno, el marco jurídico-político de la desamortización de bienes de manos muertas; dos, la relación de bienes desamortizados entre 1861-1876 y, tres, un balance general por Estados de los bienes desamortizados en el mencionado período.

${ }^{4}$ El dominio sobre los bienes que pasaban a manos muertas era perpetúo y se excluían del pago de impuestos.

5 Véase un balance historiográfico sobre la temática en De la Cruz-Vergara, 2014a: 31-65.

6 Jaramillo y Méisel, 2010: 283-321. Méisel y Salazar, 2012: 119-146. De la Cruz-Vergara, 2014a: 31-65; 2011: 203-222; 2012: 159-168.

7 Díaz Díaz, 1989: 197-199.

8 Idem. 


\section{El MARCo JURÍDICO-POLÍTICO Y CONTABLE DE LA DESAMORTIZACIÓN DE BIENES DE MANOS MUERTAS}

La expropiación de los bienes a la Iglesia, como se dijo anteriormente, se convirtió en una condición necesaria dentro del nuevo esquema reformista, debido a que, según sus exponentes, permitiría el desarrollo de la industria y, por tanto, de la economía. Una de las causas por las cuales se aprobaron estas medidas está en el hecho de que los esfuerzos legislativos y, en la práctica, que se habían realizado en las primeras décadas del siglo XIX para limitar las manos muertas no habían dado los resultados esperados.

De tal manera que hacia el año de 1847 Florentino González ${ }^{9}$, en su Informe de Hacienda, demostró cómo las manos muertas seguían dominando la propiedad sobre la tierra y cómo se habían convertido en un obstáculo para el desarrollo ${ }^{10}$. De otra parte, el asunto radicaba básicamente en lograr la separación entre el Estado y la Iglesia, y el sometimiento de ésta al primero; las discusiones giraban también en torno a la cantidad de bienes que concentraban y cómo la Iglesia utilizaba su poder para mover a las masas en el sentido que le conviniera.

A partir de $1860^{11}$, Tomás Cipriano de Mosquera se abanderó de este proceso emitiendo los decretos ${ }^{12}$ más radicales aprobados hasta el momento sobre la expropiación a la Iglesia, siendo uno de ellos el decreto de 9 de septiembre de $1861^{13}$, el cual implicó una transformación sin precedentes en cuanto a la propiedad, pues no solamente se desamortizaron los bienes eclesiásticos sino, también, los bienes civiles que estuvieran amparados bajo la figura de corporativos.

Para el buen funcionamiento y optimización de los recursos captados por la ley de desamortización se diseñó la siguiente estructura:

La máxima autoridad se concentraba en la Junta Suprema del Crédito Nacional, la cual controlaba todo el sistema; para dichos efectos, se nombraba un funcionario denominado el Agente General de Bienes Desamortizados, quien se posesionaba frente al Secretario del Tesoro Público.

9 González, 1847: 599-621

10 Entiéndase por concepto de desarrollo el establecido por las teorías económicas liberales y del que se habían apropiado las élites políticas neogranadinas de la segunda mitad del siglo XIX.

11 Galindo (1874: 102) señaló el año de 1863 como el del fin del modelo económico librecambista y el inicio de la economía moderna.

12 Recopilación de las disposiciones..., 1962, Biblioteca Luis Ángel Arango (en adelante BLAA), miscelánea 1266, pieza 7, 1-6.

13 Idem. 
En los Estados Soberanos ${ }^{14}$ los agentes principales de bienes desamortizados eran los encargados de custodiar todos los bienes; de ellos dependían los agentes subalternos especiales, que se nombraban para administrar los bienes de las corporaciones, comunidades religiosas y de beneficencia; éstos se posesionaban frente al alcalde de su circunscripción. Los agentes subalternos de Círculos estaban encargados de administrar los bienes desamortizados en los distritos; todos ellos eran de libre nombramiento y remoción, por lo cual, al tomar posesión de su cargo, lo hacían frente a la primera autoridad política del Estado.

Debido al riesgo que se corría por la cantidad de recursos que cada agente debía manejar, cada uno de ellos, al momento de posesionarse, ofrecía una garantía sobre los bienes a captar: los agentes subalternos del 3 al 5\% sobre el rendimiento de los bienes a administrar; la cuantía sobre la que se liquidaba dependía del inventario de bienes, como paso previo a la desamortización propiamente dicha. A los agentes principales se les exigía una garantía mayor debido a que estos eran los que concentraban todos los bienes en cada uno de los Estados de la Unión; ellos la presentaban sobre el 1\% del total del valor de los bienes inventariados ${ }^{15}$.

Así, mientras los agentes eran los responsables de inventariar, desamortizar, vender, rematar, arrendar, recaudar, pagar a los trabajadores de las fincas que administraban, contar los semovientes, determinar el censo, custodiar los bienes raíces, muebles y títulos de propiedad, cobrar el dinero que se adeudaba a las corporaciones y entregar los bienes rematados, el agente principal se encargaba de realizar veeduría sobre todos los informes enviados por los agentes que estaban bajo su mando.

La mecánica para el remate de los bienes era la siguiente:

1) Los bienes se remataban en el Estado Soberano en que se hallaban.

2) La organización de comisiones para los remates era presidida por el agente principal, quien anticipadamente calificaba los bienes que se iban a rematar.

3) Las adjudicaciones se asignaban al mejor postor luego de la publicación de tres pregones y concluido el término señalado para la duración de cada remate.

14 Los Estados Unidos de Colombia (1863-1886) se caracterizó por tener una estructura administrativa-territorial de unión con carácter federativo. En total se constituyeron nueve Estados soberanos: Antioquia, Bolívar, Boyacá, Cauca, Cundinamarca, Magdalena, Panamá, Santander y Tolima.

15 Idem. 
4) Los particulares podían aumentar sus propuestas por escrito sobre los lotes señalados para remate.

5) Los nombres de los proponentes se mantenían en secreto para garantizar el derecho a la igualdad.

6) Al momento de la subasta se tenía en cuenta el mejor precio.

7) Se llevaba un acta o libro en el que se escribían detalladamente los datos del remate.

8) Toda postura en la subasta se hacía por escrito.

9) El pliego de posturas se encabezaba señalando la finca que se iba a rematar, luego se remitía a la Junta Suprema para su aprobación.

10) La Junta Suprema regresaba al agente principal la aprobación para la realización de las escrituras.

11) Se enviaba una relación de las escrituras a la Junta Suprema, la que a su vez la enviaba a la Dirección de Crédito Nacional.

12) Los gastos de envíos y de escrituras corrían por cuenta del rematador.

13) En las fincas que estaban endeudadas con las fundaciones, se expresaba en el avalúo la cantidad que correspondía a la fundación y lo que ésta debía pagar al tesoro; el producto excedente quedaba en poder del rematador hasta que la Junta Suprema ordenara su entrega en dinero.

14) Las mejoras reconocidas a favor de los arrendatarios debían declararse.

15) Las fincas afectadas por fundaciones de familias quedaban hipotecadas por el valor excedente a favor de las familias de los fundadores.

16) Los censos ${ }^{16}$ a favor de los particulares o de corporaciones de manos muertas no aparecían referenciados en las escrituras si estaban inscritos como bienes desamortizados a cargo del tesoro de la Unión.

17) Los semovientes que se hallaban en las fincas se remataban por lotes de 50 cabezas $^{17}$.

La contabilidad de los bienes debía llevarse por partida doble ${ }^{18}$ y de acuerdo con los principios de la Hacienda Nacional; para ello, se abrieron cuentas a los agentes principales, a los subalternos y al agente general (véase cuadro 1).

\footnotetext{
16 Hace referencia al censo eclesiástico.

17 Idem.

18 Decreto reglamentando la administración ..., 1864, BLAA, miscelánea, 1445, pieza 1, 1-6.
} 


\section{Cuadro 1: Estructura de la CONTABILIDAD DE LOS BIENES DESAMORTIZADOS}

\begin{tabular}{|c|c|c|c|}
\hline Agentes & Cuentas & Subcuenta & Descripcion \\
\hline \multirow{9}{*}{ 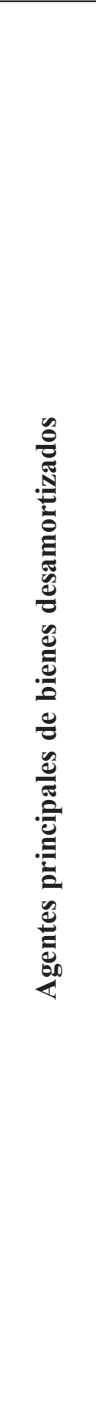 } & \multirow[t]{2}{*}{$\begin{array}{l}\text { Cuentas } \\
\text { generalísi- } \\
\text { mas } *\end{array}$} & $\begin{array}{l}\text { Caja de amorti- } \\
\text { zación }\end{array}$ & $\begin{array}{l}\text { Se debitaba con las remesas en dinero y recibos por } \\
\text { sueldos y demás gastos que el agente hacía a la res- } \\
\text { pectiva caja auxiliar de amortización }\end{array}$ \\
\hline & & Agente general & $\begin{array}{l}\text { Se debitaba con las remesas que el agente principal } \\
\text { hacía al agente general, en billetes de tesorería y vales } \\
\text { amortizados }\end{array}$ \\
\hline & \multirow[t]{3}{*}{$\begin{array}{l}\text { Cuentas de } \\
\text { créditos } \\
\text { reconocidos }\end{array}$} & $\begin{array}{l}\text { Bienes } \\
\text { desamortizados }\end{array}$ & $\begin{array}{l}\text { La cuenta de bienes desamortizados. Se acreditaba } \\
\text { con las sumas de los remates aprobados, del producto } \\
\text { de las enajenaciones diferentes a remates, recaudo de } \\
\text { los principales a plazo, réditos y arrendamientos an- } \\
\text { teriores al } 9 \text { de septiembre de } 1861\end{array}$ \\
\hline & & $\begin{array}{l}\text { Réditos y } \\
\text { arrendamientos }\end{array}$ & $\begin{array}{l}\text { La cuenta de réditos y arrendamientos: se acreditaban } \\
\text { con las sumas provenientes de los contratos de arren- } \\
\text { damientos o por rendimiento de los bienes no arren- } \\
\text { dados (que no fueran de enajenación de su valor) }\end{array}$ \\
\hline & & $\begin{array}{l}\text { Derechos de } \\
\text { títulos }\end{array}$ & $\begin{array}{l}\text { La cuenta de derechos de títulos: Partidas al débito } \\
\text { resultado de las rectificaciones de errores o por anu- } \\
\text { lación de partidas del crédito }\end{array}$ \\
\hline & \multirow[t]{2}{*}{$\begin{array}{l}\text { Cuentas de } \\
\text { recaudación }\end{array}$} & $\begin{array}{l}\text { Una a cada } \\
\text { Agente o } \\
\text { Administrador } \\
\text { subalterno }\end{array}$ & $\begin{array}{l}\text { La cuenta de agentes subalternos o administrador es- } \\
\text { pecial se debita con las sumas que, conforme a los } \\
\text { contratos de arrendamiento y a otros documentos, } \\
\text { debía recaudar en cada mes dicho agente. Se acredi- } \\
\text { taban: 1) remesas mensuales que hiciera el agente en } \\
\text { dinero y en recibos por gastos autorizados y sueldo } \\
\text { eventual; y 2) con aquellas sumas que habían sido } \\
\text { debitadas conforme a documento que, sin culpa del } \\
\text { agente, no se recauden después }\end{array}$ \\
\hline & & Rematadores & $\begin{array}{l}\text { La cuenta de rematadores se debita con las sumas en } \\
\text { deuda, procedentes de remates aprobados }\end{array}$ \\
\hline & $\begin{array}{l}\text { Cuentas de } \\
\text { caja y cartera }\end{array}$ & $\begin{array}{l}\text { Caja: Billetes } \\
\text { de tesorería; y } \\
\text { vales }\end{array}$ & $\begin{array}{l}\text { Representan cada una el movimiento de entrada y sa- } \\
\text { lida de cada uno de estos }\end{array}$ \\
\hline & $\begin{array}{l}\text { Cuentas } \\
\text { varias }\end{array}$ & $\begin{array}{l}\text { Depósitos: } \\
\text { anticipaciones; } \\
\text { y aprovecha- } \\
\text { mientos }\end{array}$ & $\begin{array}{l}\text { Las anticipaciones se debitaban de todos los gastos de } \\
\text { administración, y se acreditaban con todas las remesas } \\
\text { de comprobante de estos gastos que se hacía a la caja } \\
\text { respectiva para su legalización } \\
\text { La cuenta de aprovechamientos se acreditaban con los } \\
\text { ingresos fundamentales y definitivos que no pudieran } \\
\text { imputarse a alguna de las cuentas anteriores }\end{array}$ \\
\hline
\end{tabular}

* Las cuentas del agente general y de la caja de amortización no podían llevar otras partidas al crédito, salvo las que resultaren de rectificaciones de errores.

Fuente: Decreto reglamentando la administración ..., 1864. 
2. RELACIÓN DE BIENES DESAMORTIZADOS ENTRE LOS AÑOS 1861 A 1875

\subsection{Los bienes desamortizados entre 1861-1864}

En el primer informe sobre bienes desamortizados, a partir del decreto del 9 de septiembre de 1861, se desagregaron los bienes mediante tres conceptos: 1) Los bienes eclesiásticos propiamente dichos, que a su vez se subcategorizaron en urbanos y rurales, conventos y censos. 2) Los bienes de educación y beneficencia, a su vez subcategorizados en urbanos, rurales censos y dinero puesto a interés. 3) Los bienes de las municipalidades que hacían referencia a bienes pertenecientes al Estado, pero que se hallaban en manos muertas, subcategorizados en urbanos, rurales y censos (véase anexo 1).

El mayor número de bienes desamortizados se realizó sobre bienes propios de la Iglesia, la cual aportó al ramo de bienes desamortizados el 65\% del total; mientras que por concepto de beneficencia y educación se captó el 13\% y por bienes de las municipalidades, el $22 \%$ (ver Gráfico 1). Por concepto de bienes vendidos y en arrendamiento se captó la suma de $\$ 1.221 .086,045$, la cual constituyó el 19\% de la relación de la existencia hasta el año de 1863 , que fue de $\$ 6.351 .166,22$.

\section{GRÁFICO 1: COMPARACIÓN ENTRE BIENES PROPIOS DE LA IGLESIA Y VINCULADOS}

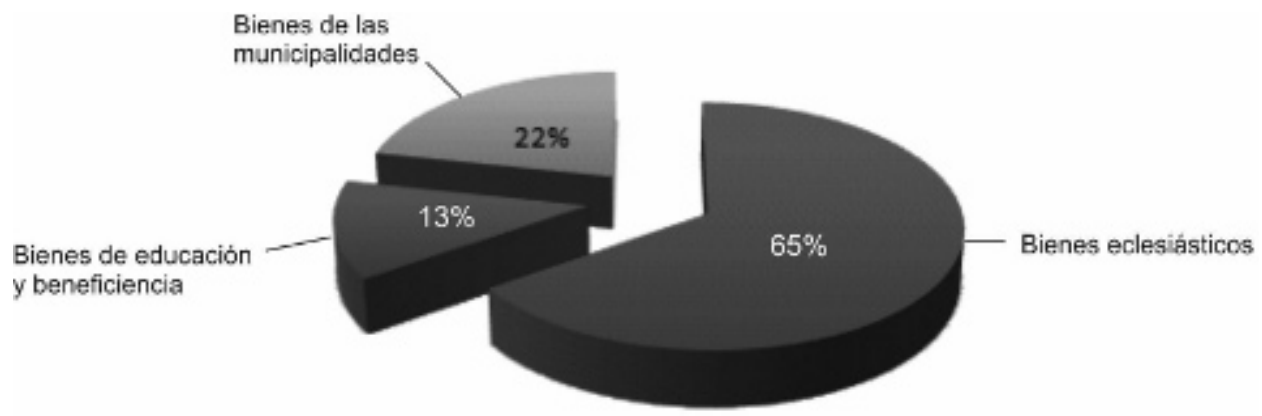

Fuente: Informe del agente general de bienes desamortizados, 1865, 14-1. Elaboración de la autora. 
Específicamente, la recaudación por Estado Soberano en el año de 1864 fue la siguiente:

CuAdro 2: PARTICIPACIÓN DE LOS ESTADOS EN LAS RENTAS POR BIENES DESAMORTIZADOS EN EL AÑO FISCAL DE 1864

\begin{tabular}{|l|r|r|r|r|}
\hline \multicolumn{1}{|c|}{ Estados /Ciudad } & Bienes raices & \multicolumn{1}{c|}{$\begin{array}{c}\text { Censos y } \\
\text { deudas }\end{array}$} & \multicolumn{1}{c|}{$\begin{array}{c}\text { Muebles y } \\
\text { semovientes }\end{array}$} & \multicolumn{1}{c|}{ Totales } \\
\hline Ciudad de Bogotá & $2,828.801,00$ & $1,026,678,60$ & $92.012,00$ & $3,947.491,60$ \\
\hline Estado de Antioquia & $73.837,00$ & $560.783,45$ & 420 & $635.040,96$ \\
\hline Estado de Bolívar & $256.590,00$ & $406.768,58$ & $4.996,05$ & $668,354,45$ \\
\hline Estado de Boyacá & $451.484,90$ & $387.811,57$ & $8.365,25$ & $847.661,72$ \\
\hline Estado del cauca & $235.068,75$ & $289.166,89$ & $6.201,00$ & $530.436,64$ \\
\hline $\begin{array}{l}\text { Estado de Cundina- } \\
\text { marca }\end{array}$ & $261.094,00$ & $296.754,98$ & $13.836,80$ & $571.685,78$ \\
\hline Estado del Magdalena & $3.636,40$ & $33.823,40$ & $3.539,20$ & $40,999,00$ \\
\hline Estado de Panamá & $188.964,15$ & $403.703,11$ & $6.727,80$ & $599.314,06$ \\
\hline Estado de Santander & $181.208,40$ & $175.453,66$ & $2.652,80$ & $359.314,86$ \\
\hline Estado del Tolima & $132.454,02$ & $198.821,72$ & $116.085,60$ & $447.361,35$ \\
\hline Total & $\mathbf{4 , 6 1 3 . 1 3 9 , 6 2}$ & $\mathbf{3 , 7 7 9 . 7 6 5 , 9 8}$ & $\mathbf{2 5 4 . 8 3 7 , 0 5}$ & $\mathbf{8 . 6 4 7 , 7 4 2 , 6 6}$ \\
\hline
\end{tabular}

Fuente: Informe del agente general de bienes desamortizados, 1865, Cuadro M.

Como se puede observar en el cuadro anterior, Bogotá, capital de la Unión, contó con mayor participación en relación con el total de la inscripción, mientras el reporte del Estado del Magdalena presupuso negligencia, oposición o falta de gestión de los agentes, ya que el porcentaje de bienes reportado se acercó a 0\%. Todos los Estados manifestaban tener dificultades para ejecutar la desamortización ${ }^{19}$; sin embargo, los agentes del Estado de Panamá ${ }^{20}$ fueron los más cumplidos y detallados en los informes, aunque interpretaron y aplicaron algunas leyes acorde con sus circunstancias, tal como la repartición de
19 Idem.
20 Idem. 
las tierras comunes amortizadas a los indígenas y excluidas de los bienes del Estado $^{21}$. Según el agente general, la Ley de 29 de mayo de $1864^{22}$ ofrecía muchos problemas en la práctica, sobre todo en lo que tenía que ver con las capellanías, en el sentido de que si la familia fundadora no había hecho uso del derecho concedido por la Ley de 2 de junio ${ }^{23}$ de 1853 , se rematarían como los demás bienes desamortizados, pero el excedente del remate del valor de la fundación le sería entregado a los que probaran que les correspondía. Esta ley condujo a que los remates fueran poco beneficiosos para el Gobierno, ya que les daba prioridad de compra a los herederos, por lo que se terminaba cambiando bonos por censo a la par, sin obtener ganancias; por tanto, se propuso que las fincas se remataran y gravaran, así el gobierno se evitaba los gastos de administración, las pérdidas por arrendamientos y el deterioro de las fincas.

En total se desamortizaron bienes inventariados por un equivalente a $\$ 8.647 .741,08^{24}$; de éstos, se remataron \$2.099.267,07, quedando en existencia por remate, $\$ 6.556 .503,62$. Estas cifras correspondían a las anotadas al momento del cierre del balance del año económico; no obstante, hay que tener en cuenta que muchas fincas quedaban pendientes de arrendarse o rematarse, situación que se veía reflejada en el siguiente año económico.

\subsection{Inscripción, ventas y remates en el año económico de 1865}

La recaudación de ese año fue muy baja, debido a que la mayoría de los agentes no enviaron la información o la que enviaron hacía referencia al último balance de 1864. En conclusión, en ese año la cuenta por bienes desamortizados bajó en la recaudación con relación al cuatrienio anterior. Sin embargo, mostró un alto índice de ventas de bienes, que ascendió a $\$ 4.883 .366,83^{25}$; es decir, se remató el $47 \%$ del total desamortizado, quedando en existencia para la vigencia del año 1866 la cantidad de $\$ 3.387 .263,04$, con un acumulado histórico en inscripción equivalente a la suma de

\footnotetext{
${ }^{21}$ Idem.

22 Informe del agente general de bienes desamortizados, 1867, BLAA, Sala de Manuscritos, miscelánea 1445, pieza 4, 1-3.

${ }^{23}$ Leyes y decretos expedidos por el Congreso, 1854, Biblioteca Nacional de Colombia (BNC), Bogotá, 60-61.

24 Idem.

25 Informe del agente general de bienes desamortizados, 1867, BNC, Fondo Pineda, pieza 2,6 .
} 
$\$ 8.843 .478,62^{26}$. En estas cuentas, los bienes de las municipalidades que estaban en manos muertas seguían entrando en la inscripción y remates de bienes desamortizados, excepto los que se habían dedicado a usos públicos, como los colegios ${ }^{27}$.

De otra parte, los problemas relacionados en el informe de 1864, siguieron sin resolverse, como la apropiación de bienes por parte de personas inescrupulosas, por lo que se impuso que los agentes debían responder por los bienes desaparecidos. ${ }^{28}$ Sobre el asunto, los agentes generales, intentando buscar explicaciones a las dificultades de los Estados, concluyeron que el problema se encontraba en los agentes subalternos, ya que éstos, aunque tenían la responsabilidad de identificar, ubicar e inscribir los bienes, contaban con muy bajos sueldos, lo que causaba dos problemas: el primero, los malos manejos de los recursos por dichos agentes, $\mathrm{y}$, segundo, que el cargo era poco atractivo, por lo que en general no se podían conseguir personas capacitadas para ocuparlos ${ }^{29}$.

\subsection{Bienes desamortizados en el año de $1866^{30}$}

El agente general de bienes desamortizados, en su informe de $1 .^{\circ}$ de enero de 1867, planteó que uno de los problemas por los cuales el ramo no había producido lo esperado era básicamente por la negligencia y falta de gestión de los diferentes agentes encargados de este ${ }^{31}$ y por los problemas que se habían causado con base en esta reforma, como la guerra de 1861, que diezmó las arcas del Estado, así como la práctica de comenzar a esconder los bienes por parte de la Iglesia, llamados «bienes ocultos». Sin embargo, resalta en su informe que el sistema adoptado para la administración del ramo era sencilla y que se podía llegar al objetivo establecido a partir de esfuerzos, disciplina y funcionarios capaces en el manejo, destacando en su gestión que en menos de siete meses de trabajo:

He despachado mil ciento quince expedientes de redenciones, reconocimiento de renta y reclamaciones varias, $[. .$.$] he dirigido a los agentes de mi dependencia$ y a los diversos empleados, mil cuatrocientas treinta y seis notas, y la oficina de
26 Idem.
27 Idem.
28 Idem.
29 Idem.
30 Informe del agente general de bienes desamortizados, 1868, BLAA, Bogotá, miscelá-
31 Idem. nea, 1445 . 
mi cargo se ha ocupado también del examen, fenecimiento e incorporación en sus cuentas de los agentes principales, y subalternos de Bogotá y Cundinamarca; todo lo cual no ha podido hacerse sino a fuerza de un constante trabajo. Debe agregarse a esto la diversidad de libros que se llenan en la oficina, entre los que deben señalarse los de la contabilidad, todos los cuales van al corriente, con excepción del Diario y Mayor, que llevan un pequeño retraso ${ }^{32}$.

Con respecto a los bienes inscritos, por ventas se llegó a la suma de $\$ 7.566 .202,50,{ }^{33}$ incluyendo el derecho de título que ascendió a la suma de $\$ 397.628,50^{34}$ y aprovechamientos por $\$ 24.067$. Producto de estas ventas se amortizaron a bonos, $\$ 7.192 .641,55$.

TABLA 1: COMPARACIÓN ENTRE BIENES INSCRITOS AVALUADOS Y REMATADOS EN EL AÑO DE 1866

\begin{tabular}{|c|c|c|}
\hline Bienes inscritos & Avaluos & Remates \\
\hline $11.067 .959,00$ & $3.311 .250,05$ & $7.566 .202,50$ \\
\hline
\end{tabular}

Fuente: Informe del agente general de bienes desamortizados, 1867. Cuadros varios.

En este año hubo más bienes inscritos que rematados (tabla 1, cuadro 3); es decir, los remates representaron un $28 \%$ menos de la cifra original. Con base en la información anterior, tenemos que los avalúos siempre estaban muy por debajo de los precios de remates, lo que supone un incremento real en el mercado de tierras.

Los bienes desamortizados sirvieron también para sostener las guerras de los Estados y de la Unión, así como para diferentes usos públicos. Analizando los ingresos por cada Estado y comparándolos con los gastos, ya sea para usos públicos o gastos de guerra (Cuadro 4), encontramos una coincidencia entre el ingreso por cada Estado y este tipo de gasto; es decir, la tendencia está en que a mayor remate, mayores gastos imprevistos. Por ejemplo: en la ciudad de Bogotá, éstos representaron el 9\%, aproximadamente, del total de los remates realizados en ese año, mientras que, en los demás Estados, a menores ingresos, menores imprevistos; sin embargo, habría que exceptuar el Estado del Tolima, en donde a pesar de presentar ingresos por remates bajos, los gastos por imprevistos fueron proporcionalmente altos.
32 Idem.
33 Idem.
34 Idem. 
Cuadro 3: Bienes RaÍCES, Muebles y SEMOVIENTES, CENSOS Y DEUdAS INSCRITOS EN EL TERRITORIO DE LA UNIÓN, HASTA 31 DE AGOSTO DE 1866

\begin{tabular}{|l|r|r|r|r|}
\hline \multicolumn{1}{|c|}{ Estados } & \multicolumn{1}{c|}{ Bienes raices } & \multicolumn{1}{c|}{$\begin{array}{c}\text { Censos y } \\
\text { deudas }\end{array}$} & \multicolumn{1}{c|}{$\begin{array}{c}\text { Muebles y } \\
\text { semovienteS }\end{array}$} & \multicolumn{1}{c|}{ Totales } \\
\hline Ciudad de Bogotá & $3.341 .773,40$ & $1.149 .145,25$ & $92.012,00$ & $4.582 .930,65$ \\
\hline Estado de Antioquia & $87.407,70$ & $701.899,20$ & 202,40 & $789.509,30$ \\
\hline Estado de Bolívar & $256.590,50$ & $393.504,65$ & $4.996,60$ & $655.091,75$ \\
\hline Estado de Boyacá & $517.395,10$ & $514.655,00$ & $5.938,20$ & $1.037 .988,30$ \\
\hline Estado de Cauca & $518.320,00$ & $1.094 .033,65$ & $14.936,35$ & $1.627 .290,00$ \\
\hline $\begin{array}{l}\text { Estado de Cundina- } \\
\text { marca }\end{array}$ & $261.094,00$ & $346.207,40$ & $13.386,80$ & $620.688,20$ \\
\hline Estado de Magdalena & $9.056,50$ & $72.345,50$ & $4.560,00$ & $85.962,00$ \\
\hline Estado de Panamá & $188.964,15$ & $429.943,00$ & $6.727,80$ & $625.634,95$ \\
\hline Estado de Santander & $181.208,40$ & $307.622,60$ & $2.652,80$ & $491.483,80$ \\
\hline Estado de Tolima & $136.022,10$ & $306.888,60$ & $108.469,60$ & $551.380,30$ \\
\hline Totales & $\mathbf{5 . 4 9 7 . 8 3 1 , 8 5}$ & $\mathbf{5 . 3 1 6 . 2 4 4 , 8 5}$ & $\mathbf{2 5 3 . 8 8 2 , 5 5}$ & $\mathbf{1 1 . 0 6 7 . 9 5 9 , 2 5}$ \\
\hline
\end{tabular}

Fuente: Informe del agente general de bienes desamortizados, 1867.

Cuadro 4: Bienes eXtraídos Para usos públicos y GaStos DE GUERRA, DEVUElTos AL DisTrito DE Bogotá EN EL AÑo DE 1866

\begin{tabular}{|l|r|r|r|}
\hline \multicolumn{1}{|c|}{ Estados } & \multicolumn{1}{c|}{ Bienes raices } & \multicolumn{1}{c|}{$\begin{array}{c}\text { Muebles y } \\
\text { semovimientes }\end{array}$} & \multicolumn{1}{c|}{ Totales } \\
\hline Ciudad de Bogotá & $543.301,00$ & $12.012,00$ & $555.313,00$ \\
\hline Estado Soberano de Antioquia & $13.310,20$ & 0,00 & $13.310,20$ \\
\hline Estado Soberano de Bolívar & $55.342,50$ & $4.346,60$ & $59.689,10$ \\
\hline Estado Soberano de Boyacá & $4.450,00$ & 0,00 & $4.450,00$ \\
\hline Estado Soberano del Cauca & $101.935,00$ & 0,00 & $101.935,00$ \\
\hline Estado Soberano de Cundinamarca & 0,00 & 768,00 & 768,00 \\
\hline Estado Soberano de Santander & $8.679,60$ & 0,00 & $8.679,60$ \\
\hline Estado Soberano de Tolima & $4.954,00$ & $34.341,55$ & $39.295,55$ \\
\hline Totales & $\mathbf{7 3 1 . 9 7 2 , 3 0}$ & $\mathbf{5 1 . 4 6 8 , 1 5}$ & $\mathbf{7 8 3 . 4 4 0 , 4 5}$ \\
\hline
\end{tabular}

Fuente: Informe general de bienes desamortizados 1867.

Según los reformadores, el objetivo de la desamortización era poner en circulación los bienes llamados de manos muertas, lo cual implicaba una reforma económica, política y social, en la que se pretendía: «arrancar del do- 
minio de corporaciones ineptas, la administración de una gran masa de riquezas en constante y creciente deterioro, para llevarla a las fuentes de la producción, poniéndola bajo el cuidadoso amparo del interés individual ${ }^{35}$, medida que había cambiado la estructura de la propiedad sobre la tierra de muchos pueblos, debido a que:

... donde antes solo se veían tristes ruinas y maleza, hoy se ven alegres o magníficas habitaciones y campos cultivados: lo que antes valía cuarenta, en lo relativo a esos bienes, hoy vale ciento, y lo que antes poco o nada producía, hoy produce lo suficiente para el sostenimiento de muchas familias y para el aumento de la riqueza nacional. A este respecto la desamortización ha llenado su propósito, está consumada; y lanzada en buena hora la reforma no habrá poder suficiente a detenerla, ni menos a hacerla retrogradar, porque las brechas que la civilización abre en las preocupaciones de los pueblos, no se cierran nunca. La desamortización, pues, está asegurada por sí misma: ha creado tantos intereses y está tan íntimamente ligada al progreso y bienestar social, que no es posible que ella pueda sucumbir. Nada hay que hacer a este respecto ${ }^{36}$.

De acuerdo con lo anterior, se observa cómo en el afán de hacer una reforma triunfante políticamente, se desconoció la realidad de los números, pues el balance seguía siendo desfavorable en cuanto al proceso en sí, ya que esta estimuló la dilapidación de bienes, los bienes ocultos y toda suerte de trampas con el fin de evitar que estos fueran a parar a las cuentas del Estado. Sin embargo, el agente general Leónidas Gutiérrez encontró que los \$11.000.000, aproximadamente, que habían entrado a las arcas del Estado eran suficientes para resolver los problemas más urgentes, sobre todo los relacionados con la deuda interior. Criticó, no obstante, que la reforma se concentrara solamente en lo político-económico, lo que hizo que se vendieran apresuradamente todos los bienes. Por otra parte, el hecho de que los acaparadores y especuladores se consolidaran como un grupo influyente en los remates volvió más compleja la reforma.

\title{
2.3. Bienes desamortizados en el año de $1868^{37}$
}

El balance general de los bienes desamortizados durante la vigencia fiscal correspondió a Eustorgio Salgar, siendo una de las acciones más importantes de su gestión solicitar a los administradores de la hacienda pública que saca-

\author{
35 Idem. \\ 36 Idem. \\ 37 Agencia General de Bienes Desamortizado, 1869, BLAA, miscelánea, 1445.
}


ran a licitación pública todos los bienes existentes, los cuales se remataron, en efecto, en cada uno de los Estados, y la segunda, la redención de censos, debido a que se cumplían los plazos establecidos para redimirlos ${ }^{38}$. Además, señaló que seguían existiendo varios problemas en el ramo, entre los más importantes de ellos era el relacionado con la entrega oportuna y clara de las cuentas de los agentes principales y subalternos, ya que estas se elaboraban con base en los bienes que entraban y no sobre los que realmente estaban en manos muertas.

Los Estados que en esta vigencia fiscal presentaron más problemas fueron los siguientes:

- $\quad$ Estado Soberano de Bolívar. Las cuentas de agosto de 1865 y el año de 1866 no fueron presentadas por el agente principal, Prudencio Blanco.

- Estado Soberano de Boyacá. El agente principal, Rufino R. Chaparro, no presentó las cuentas de los meses de octubre y noviembre de 1866 , mientras su sucesor, Buenaventura La Rota, no rindió cuentas en los meses de agosto de 1867 a febrero de 1868, como tampoco la cuenta general del año 1867-1868. Manuel Monroy no había presentado las cuentas de junio de 1868 a febrero de 1869 , ni la cuenta general del año de 1867 a 1868 (encargado del ramo en la vigencia fiscal 68-69).

- Estado Soberano del Cauca. El agente principal, Ezequiel Hurtado, no rindió todas sus cuentas generales desde el año de 1863 hasta 1866, y Antonio Paz, tampoco presentó las de los meses de mayo a julio de 1867 y la general de 1866 a 1867.

- Estado Soberano de Cundinamarca. Joaquín M. Soto no había rendido las siguientes cuentas: de abril a agosto de 1866, como tampoco la general de 1865 a 1866 como agente de los bienes de San Agustín y la Candelaria de Bogotá. Por su parte, Asisclo Castro, como agente de los bienes de la municipalidad y establecimientos de beneficencia de Bogotá, no había rendido las cuentas mensuales de 1866, así como la general de 1865 a 1866 .

- Estado Soberano del Magdalena. Miguel A. Zúñiga no había rendido las cuentas de septiembre a diciembre de 1866 como agente principal encargado. Manuel del Campo Rodríguez no rindió la cuenta general del año de 1866 a 1867, ni las cuentas mensuales de 1867 y las de enero a marzo de 1868 y los fondos respectivos.

38 Idem. 
- Estado Soberano de Panamá. Manuel María Díaz no había rendido cuentas de febrero a abril de 1867 y la cuenta general de 1867. José Goti, las de febrero a agosto de 1868, y la general de 1867 a 1868 . José María Alemán no había remitido las cuentas de diciembre de 1868, enero y febrero de 1869.

Con relación a lo anterior tenemos varios asuntos que resaltar: a) El año más crítico fue el de 1866, pues el $60 \%$ de los Estados, incluyendo a la ciudad de Bogotá, debían las cuentas. b) El Estado del Cauca debía informes desde el año 1863. c) Los agentes del Estado del Magdalena no sólo no presentaban los informes, sino que, además, en los enviados siempre se reportaba un mínimo de bienes inscritos. d) El Estado de Panamá, que en el informe del agente principal de 1864 a 1866 se resaltaba por la diligencia y buen manejo del ramo, en este informe apareció incluido en la lista de estados morosos por informes.

En este punto valdría la pena preguntarnos: ¿qué acontecimientos permitieron que en 1866 hubiera tanta crisis de informes en el ramo? Para intentar una respuesta sobre esto hay que tener en cuenta las siguientes consideraciones: a) la negligencia de muchos de los agentes en sus diferentes rangos; b) la resistencia de la Iglesia y creyentes a aceptar la norma; c) el aumento de bienes ocultos y, sobre todo, la dilapidación y los malos manejos que algunos agentes hicieron sobre los bienes que por esta vía entraban al Estado. Desde otro ángulo, y si se da por cierta la idea de que los agentes subalternos tenían mal sueldo, encontraremos otras causas; sin embargo, es preciso anotar que estos funcionarios debían firmar una garantía sobre los bienes inscritos conjuntamente con un deudor solidario. Esta situación, más la poca claridad que tenían algunas leyes, propició conductas de apropiación de los recursos del Estado. Dicho de otra manera, en este nivel el funcionario público entraba en el campo de lo privado, pues de la captación de recursos dependían sus ingresos y de estos dependía el garante; o sea, el deudor solidario y el aval del político más influyente del momento. Esta situación nos conduce a concluir que la ley misma abría la puerta para que este tipo de anomalías se convirtieran en costumbre.

Para este período se inscribieron $\$ 5.881 .048,75$, en bienes raíces; $\$ 5.902 .832,50$, en censos y deudas; $\$ 259.632,60$, en muebles y semovientes; para un total - sumando los tres conceptos - de $\$ 12.043 .513,85^{39}$. Desde el punto de vista porcentual, la ciudad de Bogotá aportó un 57\% del total recau-

\footnotetext{
39 Idem.
} 
dado, de lo que se deduce que fue en la capital en donde la reforma fue mucho más contundente. ${ }^{40}$

Comparando los bienes inscritos con los rematados encontramos que estos últimos correspondieron solamente al $27 \%$ del inventario inicial. Este caso probablemente se explica porque los semovientes desde el momento de la inscripción hasta el remate, podían sufrir toda suerte de circunstancias, tales como muerte, darlos por muertos, por desaparecidos o porque eran trasladados desde el lugar de origen en donde fueron censados e inscritos a otros lugares por fuera del control de los agentes del ramo ${ }^{41}$.

CUADRo 5: Bienes RAÍCES, MUEBleS Y SEMOVIENTES, CENSOS Y DEUdAS INSCRITOS EN EL TERRITORIO DE LA UNIÓN HASTA 31 DE DICIEMBRE DE 1868

\begin{tabular}{|l|r|r|r|r|}
\hline $\begin{array}{c}\text { Capital de la Unión } \\
\text { y de los Estados }\end{array}$ & \multicolumn{1}{c|}{ Bienes raíces } & \multicolumn{1}{c|}{$\begin{array}{c}\text { Censos y } \\
\text { deudas }\end{array}$} & $\begin{array}{c}\text { Muebles y } \\
\text { semovientes }\end{array}$ & \multicolumn{1}{c|}{ Totales } \\
\hline Ciudad de Bogotá & $3.352 .473,40$ & $1.208 .253,00$ & $92.012,00$ & $4.652 .738,40$ \\
\hline Estado de Antioquia & $87.407,70$ & $701.899,20$ & 202,4 & $789.509,30$ \\
\hline Estado de Bolívar & $256.590,50$ & $522.367,15$ & $4.996,60$ & $783.954,25$ \\
\hline Estado de Boyacá & $517.395,10$ & $528.468,50$ & $5.938,20$ & $1.051 .801,80$ \\
\hline Estado del Cauca & $547.970,15$ & $1.198 .397,95$ & $14.936,35$ & $1.761 .304,45$ \\
\hline Estado de Cundinamarca & $262.694,00$ & $354.420,20$ & $13.386,80$ & $630.501,00$ \\
\hline Estado del Magdalena & $9.056,50$ & $72.345,50$ & $4.560,00$ & $85.962,00$ \\
\hline Estado de Panamá & $188.964,15$ & $443.850,20$ & $6.727,80$ & $639.542,15$ \\
\hline Estado de Santander & $498.230,10$ & $528.468,50$ & $8.402,85$ & $1.035 .101,45$ \\
\hline Estado del Tolima & $160.267,15$ & $344.362,30$ & $108.469,60$ & $613.099,05$ \\
\hline Total & $\mathbf{5 . 8 8 1 . 0 4 8 , 7 5}$ & $\mathbf{5 . 9 0 2 . 8 3 2 , 5 0}$ & $\mathbf{2 5 9 . 6 3 2 , 6 0}$ & $\mathbf{1 2 . 0 4 3 . 5 1 3 , 8 5}$ \\
\hline
\end{tabular}

Fuente: Agencia General de bienes desamortizados 1869, Cuadro 3.

Si tomamos como referencia el análisis comparativo de los presupuestos de gastos y rentas, trascurrido entre el $1 .^{\circ}$ de septiembre de 1863 y el 31 de agosto de $1867^{42}$ (véase gráfica 2), tenemos que el total de las rentas recaudadas fue de $\$ 15.488,094$, de los cuales la renta por bienes desamortizados

\footnotetext{
40 Idem.

41 De la Cruz-Vergara, 2012: 134.

42 Memoria del secretario del Tesoro y..., 1870, BLAA.
} 
ascendió a la suma de $\$ 6.924 .311^{43}$, lo que correspondía a una participación del $45 \%$ en el cuatrienio del total del presupuesto de los Estados Unidos de Colombia.

GrÁFICO 2: PARTICIPACIÓN EN PORCENTAJE DEL RAMO DE BIENES DESAMORTIZADOS EN EL INGRESO POR RENTAS DEL PRESUPUESTO GENERAL DE LA NACIÓN EN EL CUATRIENIO 1863-1867

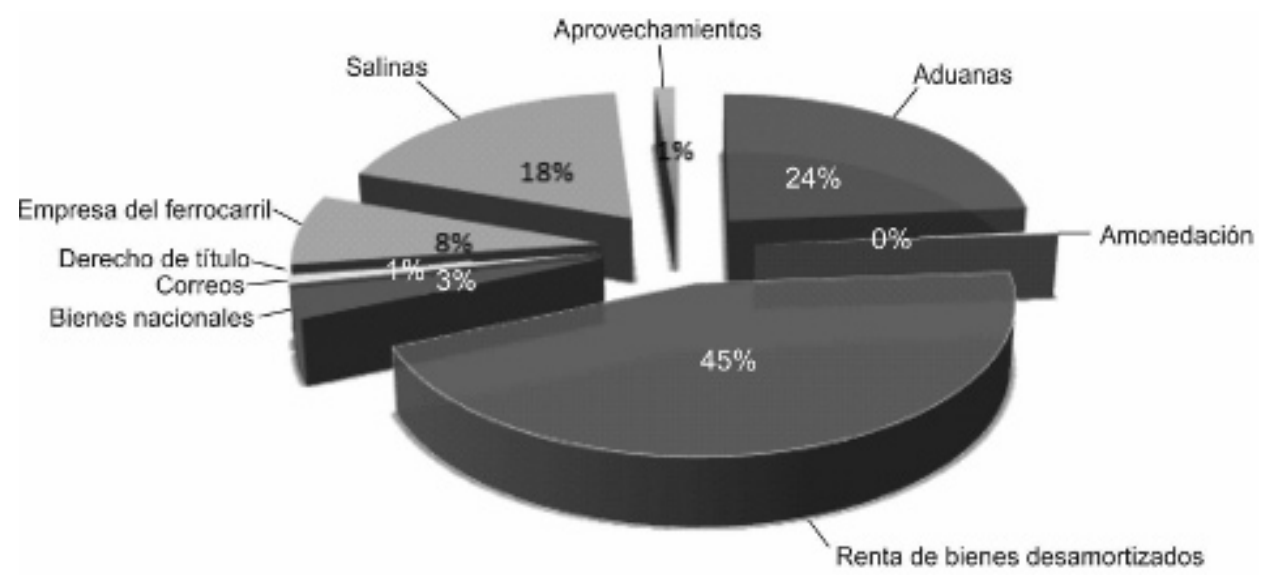

Fuente: Memoria del Secretario del Tesoro y Crédito Nacional al Congreso de 1870, 1870. Elaboración de la autora.

\subsection{Bienes desamortizados en el año económico de $1869^{44}$}

Con la promulgación de la Ley de 02 de julio de $1869^{45}$ y del decreto ejecutivo de 31 de julio del mismo año, la dinámica de la desamortización de bienes de manos muertas cambió, pues los agentes principales, encargados de los bienes en cada Estado, dejarían de reportar al agente general de bienes desamortizados; por tanto, sus informes serían enviados a la Oficina General de Cuentas, por lo que a partir de este momento las cuentas quedaron fragmentadas en la Hacienda Nacional. Con base en la ley reformatoria del 02 de

\footnotetext{
43 Valor neto.

44 Informe del agente general de bienes desamortizados, 1870, BNC, Fondo Pineda, 868, pieza 2.

45 Idem.
} 
junio, se aprobó la resolución de 30 de junio del mismo año en donde se expresaron nuevos lineamientos para el ramo de bienes desamortizados, los cuales fueron:

- $\quad$ Las agencias principales podían recibir en pago de derechos de títulos y réditos de censos, los cupones de renta sobre el tesoro al portador, vencidos desde el 1 de septiembre de 1868.

- Desde el $1 .^{\circ}$ de septiembre de 1869 quedaban fuera de circulación legal los vales de renta sobre el tesoro correspondiente a emisiones anteriores.

- Los pagos en cupones por réditos de censos no podían ser admitidos sino en las agencias principales y en la Agencia General de bienes desamortizados, por ser estas oficinas las encargadas de la recaudación y cuenta de dichos réditos.

- Las agencias de bienes desamortizados no serían oficinas pagadoras y por tanto los pagos que debían hacerse por gastos y amortizaciones de documentos se tramitarían en las administraciones de Hacienda, en el caso de los agentes principales, y en la Tesorería General para el caso de la Agencia General.

- La Administración de Hacienda, que llevaba por separado la contabilidad de los bienes desamortizados, abriría una cuenta a cupones, la cual sería debitada con los ingresos en cupones y acreditada con cargo a la Administración de Hacienda ${ }^{46}$.

En el año de 1869 el ramo contaba con $\$ 1.188 .937,30$ en existencia por valor de bienes registrados, lo cual se convirtió en fondo líquido para la deuda interior ${ }^{47}$. Por ventas hasta el año 1869 se registró la suma de $\$ 10.399 .444,95$, teniendo un ingreso efectivo con relación al avalúo ${ }^{48}$ de $\$ 6.649 .548,30$.

\footnotetext{
46 Idem.

47 Idem.

48 El avalúo se registró en \$3.883.481,20.
} 


\subsection{Bienes desamortizados en la vigencia de 1870-187149}

Los bienes rematados del fondo de bienes desamortizados, según la Secretaría del Tesoro y Crédito Nacional, fueron los siguientes:

Cuadro 6. Relación de los BIEnes aVAluados, REMATAdos Y RÉditos, $1870-1871^{50}$

\begin{tabular}{|l|r|r|r|r|}
\hline $\begin{array}{c}\text { Capital de la Unión y } \\
\text { de los Estados }\end{array}$ & $\begin{array}{c}\text { Bienes } \\
\text { avaluados }\end{array}$ & $\begin{array}{c}\text { Bienes } \\
\text { rematados }\end{array}$ & $\begin{array}{c}\text { Réditos y } \\
\text { arrenda- } \\
\text { mientos }\end{array}$ & $\begin{array}{c}\text { Diferencia } \\
\text { entre los } \\
\text { avalúos y los } \\
\text { remates }\end{array}$ \\
\hline Cundinamarca (Bogotá) & $129.990,10$ & $523.425,00$ & $7.236,75$ & $393.434,90$ \\
\hline Estado de Antioquia & & & $2.174,07$ & \\
\hline Estado de Bolívar & $18.750,00$ & $33.027,00$ & $2.504,13$ & $14.277,00$ \\
\hline Estado de Boyacá & $13.165,00$ & $137.562,00$ & & $124.397,00$ \\
\hline Estado del Cauca & & & & \\
\hline Estado del Magdalena & & & & \\
\hline Estado de Panamá & & & & \\
\hline Estado de Santander & 620,00 & $1.900,00$ & & $1.280,00$ \\
\hline Estado del Tolima & $7.886,40$ & $42.200,00$ & $3.758,92$ & $34.313,60$ \\
\hline Total & $\mathbf{1 7 0 . 4 1 1 , 5 0}$ & $\mathbf{7 3 8 . 1 1 4 , 0 0}$ & $\mathbf{1 5 . 6 7 3 , 8 7}$ & $\mathbf{5 6 7 . 7 0 2 , 5 0}$ \\
\hline
\end{tabular}

Fuente: Estadística del Comercio Exterior y de Cabotaje y de los demás ramos relacionados con la Hacienda Nacional, correspondiente al año comprendido entre 1870-1871, 1872: 219-220.

De acuerdo con el cuadro anterior, los ingresos por bienes desamortizados en el bienio 1870-1871, representaron solamente el 38,63\% de lo recaudado en el año fiscal de 1868, lo cual nos muestra un descenso bastante significativo en la captación de recursos por dicho concepto; siendo una de las razones para ello la reforma realizada a la desamortización en el año de 1869 , la cual no permitió que se siguieran consolidando los ingresos por desamortización en la Agencia General, sino que las cuentas de los Estados quedaron dispersas en la Oficina General de Cuentas. Es conveniente anotar que los bienes relacionados hacían referencia a los que habían sido aprobados por el Ejecutivo, es decir, aquellos que por su cuantía debían pasar por esta instancia. De otra parte, entre el período de 1869 a 1870, las erogaciones en dinero para gastos

49 El año fiscal se contaba de agosto a agosto. 
nacionales del departamento de bienes desamortizados ascendieron a $\$ 7.852$, 25 , y lo captado por censos a $\$ 4.929 .818,88$, de los cuales se redimieron en el año 1869 los siguientes:

- Con bonos flotantes que ganaban el interés del 3\% desde el $1 .^{\circ}$ de marzo de 1862 , la suma de $\$ 15.677,50$.

- Con bonos flotantes de capitalización, \$9.431,70.

- Con vales de renta sobre el tesoro al portador, $\$ 839,38$. Para un total en redención de $\$ 25.948,58^{50}$.

El secretario del Tesoro y Crédito, en el informe de 1871, planteaba que la marcha del negocio de bienes desamortizados desde cierto tiempo atrás se había vuelto lenta debido a las siguientes causas ${ }^{51}$ :

- Los rezagos de los bienes estaban muy diseminados y con poco valor en el mercado, lo que hacía imposible impulsar el negocio.

- La supresión de los agentes principales del ramo en los Estados y el exceso de funciones de los empleados a los que se les encargó el asunto, no les permitía dedicarle el tiempo necesario, lo que redundó en el decaimiento del ramo y en la pérdida de importancia con relación a los años anteriores.

- El sistema de remate se encontraba relativamente estancado, ya que, por una parte, el gobierno no aprobaba nuevos remates y el valor de estos no alcanzaba a la quinta parte del avalúo y, por otra, los rematadores no aumentaban sus ofertas por el temor a invertir sobre documentos cuya cotización era variable.

En este año los ingresos por bienes fueron de $\$ 220.734,80$ y los remates por $\$ 1.094 .946,40^{52}$, incluyendo en esta última cifra las existencias del año anterior. En el mismo, se ordenó al agente general que realizara un inventario con el fin de consolidar las cuentas del ramo desde el momento de la desamortización, encontrando éste que el mayor problema hacía referencia a la poca claridad en la información y a que las agencias subalternas no tenían disposición para enviar las cuentas, así como tampoco en aclararlas ${ }^{53}$. Con datos parciales llegó a la conclusión de que en el ramo, desde 1861 hasta

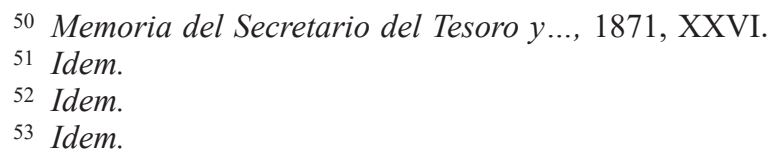


1871, se habían inscrito bienes por la suma de $\$ 9.948 .317,17$ y que las ventas y los remates habían ascendido a $\$ 7.714 .430,00$, encontrando una existencia de $\$ 2.133 .888,15$.

\subsection{Bienes desamortizados en el año económico de $1871^{54}$}

El objetivo de la desamortización, según el agente J. Herrera ${ }^{55}$ se centraba fundamentalmente en vender los bienes que estaban en manos muertas y redimir los censos, con el fin de que pasaran a manos de los particulares, de tal manera que el Estado pudiera gravarlos con los impuestos correspondientes. Según el Secretario de Hacienda, al cierre del año fiscal 1871-1872 no se había puesto en marcha eficientemente la Ley de 22 de mayo de 1865, la cual ordenaba que a 30 de junio de $1866^{56}$ no existieran en poder de la nación ${ }^{57}$ bienes desamortizados.

Como posibles causas para que en seis años no se hubiera llevado a cabo tal decisión deben considerarse las siguientes: 1) Haber anexado las agencias de bienes de manos muertas a las administraciones de Hacienda de los Estados, las cuales no tenían tiempo para dedicarle a este asunto. 2) Debido a que el sueldo de los empleados del ramo dependía del número de fincas que tuvieran en administración, estos no se preocupaban por las ventas, ya que se les disminuía el sueldo; es decir, por cada finca que se vendía se disminuían los ingresos del agente, mientras que las fincas arrendadas les garantizaban un porcentaje del valor del alquiler 3) El período de licitación, que era de 60 días, se consideraba muy largo. 4) La política que adoptaron algunos agentes de no rematar fincas que no excedieran seis veces su avalúo. 5) El abuso de algunos rematadores que desertaron de los remates, amparados en que los empleados no aplicaban la ley, en el sentido de cobrar los plazos vencidos, lo cual condujo a que muchos tuvieran las fincas por años y luego las abandonaban para que fueran inscritas nuevamente.

Otro tema que no se había podido resolver era el referente al pago de las mejoras, ya que estas terminaban costando más que los terrenos a rematar, tal como el caso de los lotes de Egipto, San Diego y Molino de Cubo en Bogotá, que el Estado vendió sin reconocer a los poseedores los costos por mejoras. Estos se dividieron en 254 lotes más pequeños, adquiridos por igual número

54 Informe del agente general de bienes desamortizados, 1874, BNC, Fondo Pineda, 868, pieza $3,1-47$.

55 Idem.

56 Memoria dirigida al ciudadano Presidente..., 1872: 53.

57 Entendido este concepto desde el aspecto jurídico y político. 
de familias, las cuales estuvieron en peligro de ser lanzadas de sus viviendas por pleitos sobre las mejoras; asunto en el que tuvo que intervenir el Congreso; en todo caso, esto evidencia la poca claridad que se tuvo entre la teoría y la práctica en el tema relacionado con las mejoras, pues, aunque la ley no las reconocía, los dueños de estas las pleiteaban con el comprador de los bienes en remate.

En el año económico de 1872 los remates ascendieron a \$472.215,13 (Cuadro 7), con una ganancia adicional, con relación a los avalúos, de $\$ 287.584,00$; si se suman los derechos de título, el ingreso total por remates de bienes raíces fue de $\$ 490.678,15$, pero, según el Secretario de Hacienda, llegaba a los $\$ 500.000,00$, debido a que se habían rematado unas cincuenta fincas más que no se hallaban reflejadas en estas cuentas.

CuAdro 7: INGRESOS REFERENTES AL AÑO ECONÓMICO DE 1872

\begin{tabular}{|c|c|c|c|c|}
\hline N. ${ }^{\circ}$ de Fincas & Avalúo & Remate & Derecho de titulo & Semovientes \\
\hline 126 & $184.631,00$ & $472.215,00$ & $18.463,15$ & 15.876 \\
\hline
\end{tabular}

Fuente: Memoria presentada al presidente de los Estados Unidos de Colombia por el Secretario del Tesoro y Crédito Nacional, 1873.

\subsection{Bienes desamortizados en el año de 1873}

Debido a la decadencia de la reforma, el ramo se dedicó a rematar los bienes que tenía en existencia, pues algunos Estados mostraron dificultades para dichos remates, como es el caso del Estado del Tolima, cuyos bienes fueron rematados por la Agencia General desde Bogotá. Sobre estos el agente reportó que incluso se vendieron a mejor precio que el que se hubiera podido obtener en Tolima. Con estas ventas, más otras que habían quedado refundidas en la Hacienda Nacional, el Estado del Tolima finiquitó la existencia de bienes desamortizados. En los demás Estados también quedaron bienes pendientes de rematar, lo cual había retrasado la suspensión de la desamortización ${ }^{58}$, la que se suponía que debía concluir antes de 1869 .

\footnotetext{
58 Idem.
} 
Son varias las causas para este atraso, sin embargo podemos señalar como relevantes las siguientes:

1) Haber delegado en los Administradores de Correos la función que hacían los agentes principales. Esta decisión condujo a que estos concentraran demasiadas funciones, por lo que la desamortización dejó de atenderse, pues los administradores de correos no tenían tiempo ni interés en esta nueva función sobre la que no se les reconocía un céntimo.

2) Falta de coherencia entre las funciones del Administrador de Correos, que permanecía en su oficina, y las necesidades de la desamortización que requerían que el agente de bienes desamortizados estuviera moviéndose por todo el territorio del Estado con el fin de visitar, inspeccionar y vigilar constantemente a los agentes subalternos.

Con base en los anteriores problemas relacionados con el ramo se propuso, por parte del agente de ese año, lo siguiente:

- Que la Agencia General pudiera rematar los bienes en existencia de cada uno de los Estados; el fundamento de dicha medida se hallaba en el hecho de que las fincas no se compraban por necesidad inmediata, sino como una inversión a la cual se le sacaban las utilidades a partir del agiotaje, de tal manera que la licitación no estaba en proporción con las necesidades de las personas, sino en proporción del número de tenedores de los papeles que se admitían en pagos.

- En consecuencia, las fincas que se remataban en los Estados se vendían siempre a un precio inferior en relación con el avalúo; en cambio, en la Agencia General se vendían a un mayor precio debido a que había más postores en el remate, ya que en la capital de la Unión circulaban los documentos de créditos admisibles en los remates y, además, se hallaban todos los negociadores en papeles, que eran los que concurrían a las licitaciones ${ }^{59}$.

- Por otra parte, el Congreso debía legislar para corregir la situación anómala del ramo, con el fin de que se hicieran cargo de este personas competentes o se restituyeran los agentes en donde se necesitaran o se creara una dependencia en la Administración de Correos para manejar la desamortización.

59 Idem. 
- Tomar el control del Ramo de Bienes Desamortizados era fundamental para evitar los errores comunes en la contabilidad sobre los bienes desamortizados; como ejemplo tenemos el caso de Popayán, en donde el gobernador en mayo de 1873, rindió un informe en el que expuso que la existencia en bienes desamortizados provenientes del balance del año anterior era de $\$ 1.462 .895,79$ pero, como el inventario formado en ese año arrojó con respecto al Cauca una existencia en bienes de \$309.092,07, resulta una diferencia de \$1.153.803,72, entre lo expuesto por el gobernador y el balance del año de 1872, demostrando con ello que no se sabía con exactitud cuál era la situación de los bienes ${ }^{60}$ desamortizados en ese año.

En el año económico terminado, a 31 de agosto de 1873, el producto del ramo ascendió a $\$ 238.148,78$, más lo producido desde el $1 .^{\circ}$ de septiembre hasta el 31 de diciembre, que fue de $\$ 54.258,25$, sumó un total de $\$ 292.408,03$ de los cuales quedó una existencia a 31 de diciembre de $\$ 8.452,17^{61}$.

\subsection{Bienes desamortizados en el año de 187462}

Este año comenzó con las reformas al ramo por la Ley 58 de 187463 , que el agente general había solicitado para destrabar los problemas que hacían que este se moviera lentamente y, sobre todo, que impedían terminar con la desamortización. Así, el poder Ejecutivo autorizó que los remates se celebraran en la capital de la Unión debido a que la experiencia había demostrado que en aquélla las licitaciones eran más ventajosas que en algunos Estados.

Para completar esta acción se puso también en funcionamiento otra estrategia que consistía en sacar simultáneamente a remate los bienes, en día y hora, tanto en la capital de la Unión como en el Estado en donde estaban ubicados, de tal manera que se aprobara la mejor oferta de acuerdo con los intereses nacionales. Como producto de esta acción, se remataron bienes simultáneamente en la Agencia General y en los Estados de Santander y Tolima, avaluadas en $\$ 11.088,47$ y vendidas por la suma de $\$ 55.340,00$ que fue el mayor precio que se obtuvo en los remates simultáneos.

\footnotetext{
60 Idem.

61 Idem.

62 Informe del agente general de bienes desamortizados, 1876, BNC, Fondo Pineda, 868, pieza 6 .

63 Constitución y leyes de los Estados Unidos de Colombia..., 1875, BNC, Fondo Quijano, 566, pieza 3, 1094-1095.
} 
El monto total del avalúo de las fincas en todos los Estados fue de \$ $21.224,47$ y el producto de las ventas fue de $\$ 142.435,00$, dando una utilidad de \$121.410,52 en el año económico de 1874, sin incluir los derechos de título por $\$ 2.102,45$ (Cuadro 8). Sobre la anterior relación podemos expresar que, a través de todo el proceso desamortizador, las fincas ubicadas en Bogotá y Cundinamarca, en términos generales, costaban más, tanto en el avalúo como en el precio de remate; dicha causa puede encontrarse en que, desde la Colonia, en la región de la sabana correspondiente geográficamente a las administraciones territoriales señaladas se hallaban grandes haciendas aptas tanto para el cultivo como para la ganadería. De otro lado, comparando el precio de venta de una sola finca en Cundinamarca con el de las 17 rematadas en Tolima, tenemos que se comprueba lo expresado, en el sentido de que la tierra tenía un mayor valor en la capital debido a que era allí en donde se encontraban los mayores inversionistas en bienes. Esto lo demuestra el hecho de que el precio de las tierras, no obstante estuvieran en otro Estado, se incrementaba si éstas se remataban en Bogotá.

Si comparamos los datos del año 1873 con los de 1874, tenemos que proporcionalmente mejoraron las rentas debido a que en 1873 se remataron 57 fincas por $\$ 127.278,92$, avaluadas por $\$ 62.652,28$, mientras que en 1874 se remataron 27 fincas por valor de 142.425,00, siendo la diferencia de $\$ 15.156,08^{64}$.

Con relación a los semovientes, se contabilizaban ganados, caballos y ovejas. Este fue un renglón que nunca mostró un comportamiento importante debido a que muchos Estados mandaban cuentas inexactas. En este año se vendieron 851 cabezas de ganado, avaluadas en $\$ 4.255,00$ y rematadas por $\$$ $4.270,00$, y 92 caballos, avaluados por $\$ 368.000,00$ y vendidos por el mismo precio; tales transacciones procedían del Estado de Panamá. De estos semovientes avaluados y autorizados, se verificaron remates por la cantidad de $\$ 4.742 .00$. Los precios del ganado mayor y menor oscilaron entre los siguientes valores: ovejas, en el Estado de Cundinamarca, a 80 centavos; cabezas de ganado, en Panamá, a \$5 pesos; caballos, a \$4 ó \$5 pesos, dependiendo de cada Estado.

En este año se habían corregido muchos de los problemas que estaban pendientes, lo que fue posible gracias a la Ley 58 de $1874^{65}$ que agilizó todos los procedimientos, siendo uno de los más importantes la simplificación del

64 En esta no se tiene en cuenta el número de fincas en relación con el precio de la hectáreas sino el conjunto del bien. Es decir, no existía una reglamentación en los Estados Soberanos y en la Unión que determinara el precio de venta por área.

${ }_{65}$ Idem. 


\section{Cuadro 8: Relación de aVAlúos y Remates EN El AÑo ECONÓMiCO DE 1874}

\begin{tabular}{|l|c|c|c|c|c|}
\hline $\begin{array}{c}\text { Capital de la Unión } \\
\text { y de los Estados }\end{array}$ & $\begin{array}{c}\text { No de } \\
\text { fincas }\end{array}$ & $\begin{array}{c}\text { Bienes } \\
\text { avaluados }\end{array}$ & $\begin{array}{c}\text { Venta por } \\
\text { remates }\end{array}$ & $\begin{array}{c}\text { derechos } \\
\text { de titulo }\end{array}$ & Total \\
\hline Cundinamarca & 1 & $3.784,00$ & $55.000,00$ & & \\
\hline Estado de Bolívar & 2 & $1.000,00$ & $1.206,00$ & & \\
\hline Estado de Boyacá & 5 & $2.070,00$ & $11.520,00$ & & \\
\hline Estado del Cauca & & $2.200,00$ & $2.240,00$ & & \\
\hline Santander & 2 & $2.240,00$ & $30.100,00$ & & \\
\hline Estado del Tolima & 17 & $9.930,47$ & $42.369,00$ & & \\
\hline Total & $\mathbf{2 7}$ & $\mathbf{2 1 . 2 2 4 , 4 7}$ & $\mathbf{1 4 2 . 4 3 5 , 0 0}$ & $\mathbf{2 . 1 0 2 , 4 5}$ & $\mathbf{1 4 4 . 5 3 7 , 4 5}$ \\
\hline
\end{tabular}

Fuente: Informe del agente general de bienes desamortizados, 1875.

tiempo de venta, lo que hizo posible el aumento de los caudales; muestra de ello fue la celeridad y mejoría en la eficiencia que reportó el Estado del Tolima. Por otra parte, en cuanto a la redención de censos, la misma Ley 58 aprobó iniciar procesos ejecutivos contra todos los deudores del Estado por este concepto, de tal manera que se abrieron 246 juicios distribuidos en todos los Estados, concentrándose la mayoría de ellos en Antioquia (130) seguidos de Tolima (52), Boyacá (31), Bolívar (16), Cundinamarca (12) y Santander (5), mientras que en Cauca, en Magdalena y Panamá no se registraron juicios ejecutivos.

A pesar del interés del Estado por recuperar los bienes, esta figura (juicios ejecutivos) se contraponía a los intereses de los particulares, por lo cual el Congreso acogió la idea de los bancos hipotecarios ${ }^{66}$, los que podían conservar el principio fundamental de la reforma; es decir, fortalecer y proteger la propiedad privada individual y, por tanto, la industria y el espíritu de empresa. Para desarrollar tal iniciativa y garantizar los bienes que entrarían en depósito, se expidió la Ley 66 de $1873^{67}$, articulado que iba en contravía con otras leyes y ordenanzas emitidas para garantizar la desamortización. ${ }^{68}$ En cuanto a la amortización de documentos, entre el año económico de 1873 a 1874 , el ramo captó $\$ 124.742,55$ por bonos flotantes; por billetes, la suma de $\$ 13.582,95$ y por cupones $\$ 11.444,20$. En total, y sumando las órdenes de pago desde el año 1870, por amortización se captó la suma de \$153.982,95.

\footnotetext{
66 Memorias del Secretario del Tesoro y..., 1875: XVIII-XXI.

67 Idem.

68 Idem.
} 
Aunque para esta época se habían corregido muchas de las falencias del ramo, se siguieron realizando modificaciones tendientes básicamente a la liquidación de la reforma; de tal manera que se modificó la configuración inicial de las agencias de bienes desamortizados, sobre todo suprimiendo algunas de ellas. Así, la agencia de Bogotá se fusionó con la de Cundinamarca; las agencias subalternas del $2 .^{\circ}$ círculo de la ciudad de Cartagena, de Lorica y la Administración Subalterna de Hacienda Nacional en Mompóx se anexaron a la Administración principal de la Hacienda Nacional del Estado. En el caso del Estado de Boyacá, solamente quedó la Agencia Especial del extinguido monasterio de Santa Clara y la Administración subalterna de Hacienda Nacional encargada del ramo de bienes desamortizados. La otra modificación importante fue la del Estado Soberano del Tolima, ya que desapareció como agencia del ramo, pasando las existencias y remates al agente general y a la Hacienda Nacional.

\subsection{Bienes desamortizados en el año de 1875}

En el año de 1875 el agente general se dedicó básicamente a realizar correcciones al ramo, ya que los ingresos en ese año, aunque fueron ligeramente superiores a los del año 1874, estuvieron significativamente por debajo de los del año de 1873, lo que implicaba que en efecto la medida estaba llegando a su fin, no precisamente porque el Estado la estuviera concluyendo, sino, básicamente, por la decadencia misma de esta. De este modo, el grueso de los bienes del año 1875 provenía de las existencias del año 1874, incorporándose 51 nuevos bienes por un valor de $\$ 22.421,20$. Se remataron en el año referenciado 78 fincas (Cuadro 9), las cuales estaban avaluadas en $\$ 39.784,50$ y rematadas por $\$ 190.441,00^{69}$, de tal manera que el Estado tuvo un incremento entre el precio de avalúo y el de venta de $\$ 150.656,50$, más los derechos de títulos, situación que demuestra la valorización de los bienes en el mercado. La existencia a 31 de diciembre de 1875 fue de 162 fincas avaluadas en $\$ 256.060,50^{70}$.

En cuanto a los semovientes, su cantidad seguía siendo imprecisa, como en el caso de Cundinamarca ${ }^{71}$ en donde el ganado lanar era dado a los párrocos, quienes a su vez se lo entregaban a algunos vecinos indígenas labriegos, que solamente se interesaban en el ganado cuando eran vigilados por el ma-

\footnotetext{
69 Informe del Agente General de bienes desamortizados, 1876, BLAA, miscelánea, 1445.

70 Idem.

71 Idem.
} 
CUADRO 9: RELACIÓN DEL RAMO DE BIENES DESAMORTIZADOS DISCRIMINADO POR ESTADO EN LA VIGENCIA ECONÓMICA DE 1875

\begin{tabular}{|l|r|r|r|r|}
\hline \multicolumn{1}{|c|}{ Estados } & Fincas & Avalúos & Precio de venta & $\begin{array}{c}\text { Derecho de } \\
\text { titulo }\end{array}$ \\
\hline Bolívar & 31 & $15.316,00$ & $24.873,00$ & \\
\hline Boyacá & 24 & $14.426,50$ & $136.622,00$ & \\
\hline Cauca & 11 & $9.128,30$ & $21.535,00$ & \\
\hline Magdalena & 6 & 513,70 & $4.276,00$ & \\
\hline Santander & 2 & 204,00 & $1.820,00$ & \\
\hline Tolima & 4 & 196,00 & $1.315,00$ & \\
\hline Totales & $\mathbf{7 8}$ & $\mathbf{3 9 . 7 8 4 , 5 0}$ & $\mathbf{1 9 0 . 4 4 1 , 0 0}$ & $\mathbf{3 . 9 7 8 , 4 5}$ \\
\hline
\end{tabular}

Fuente: Informe del agente general de bienes desamortizados, 1876, 1 .

yordomo o cuando recibían amenazas religiosas del párroco, al que consideraban su amo y señor, pero una vez cortada la relación con estos, los bienes desaparecían o morían ${ }^{72}$.

Los censos constituyeron uno de los rubros más complejos, puesto que todos no se inscribieron, de tal suerte que había censos desde antes de 1861, por lo que el dato exacto en el año 1875 sobre la redención no fue claro. Sin embargo, se redimieron en esa vigencia procedente de los Estados de Antioquia, Bolívar, Boyacá, Cundinamarca, Santander y Tolima $\$ 633.271,45^{73}$, siendo Boyacá el que mayores censos redimió según esta relación. En el año 1876, y según el agente general, ya se podía dar por finalizada la desamortización, quedando pendiente los juicios ejecutivos y algunos censos, para lo cual se propuso la creación de una oficina de cobros dependiente de Hacienda Nacional y que se liquidara el Ramo de Bienes de Manos Muertas ${ }^{74}$.

\section{BALANCE GENERAL Y POR ESTADO DE LOS BIENES DESAMORTIZADOS ENTRE 1861 Y 1875}

Consolidando las cuentas de bienes inscritos y rematados, tenemos que el auge de la desamortización ocurrió entre los años 1866 y 1868, siendo la de este último año la más importante, pues se captaron recursos por $\$ 10.752 .318,95$,

\footnotetext{
72 Idem.

73 Idem.

74 Idem.
} 
mientras el más bajo por remates fue el año económico de 1874 , en donde por el mismo concepto se captó $\$ 144.537,45$. De otro lado, como se puede ver en el Gráfico 3, la decadencia del ramo se hizo evidente a partir de 1870, logrando sus niveles más bajos, tanto de remates como de bienes inscritos, por lo que el agente anunció en el año 1875 que en 1876, y de acuerdo con la situación planteada, se podía dar por cerrado el negocio de la desamortización.

Grafico 3: Auge y DECADENCIA DEL RAMO DE BIENES DESAMORTIZAdoS

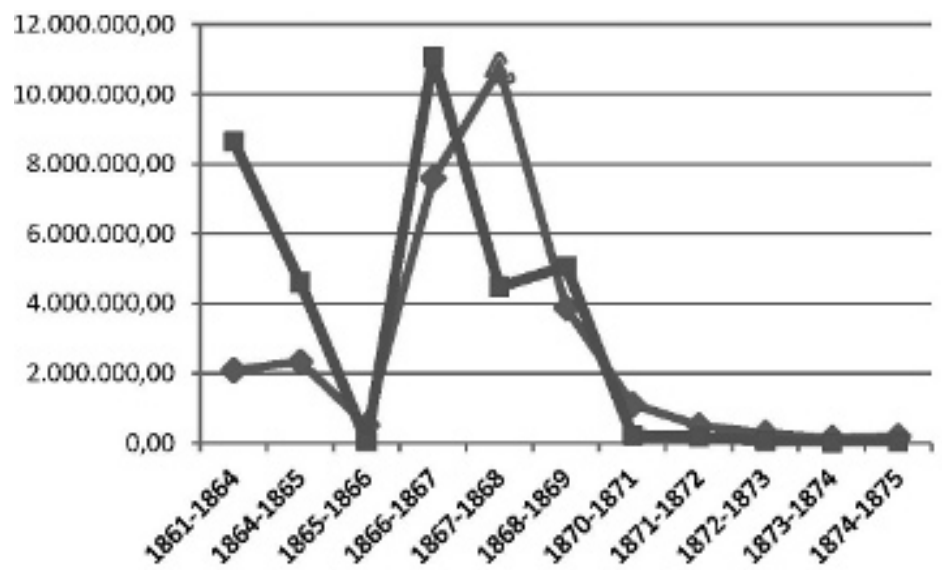

$\leadsto$ Remates

Fuente: De La Cruz-Vergara, 2012.

No obstante, vale aclarar que el anterior análisis está realizado sobre las cuentas reportadas por cada Agencia Principal en los años estudiados, ya que según el balance realizado por el agente general, Miguel Gutiérrez, en el año de 1872 el ramo de bienes desamortizados había captado por inscripción de bienes \$ 9.848.317,17, mientras, según el agente general Miguel Salgar, la desamortización pasaba de $\$ 12.000 .000$.

Lo anterior significa que entre ambos agentes había divergencias en cuanto a la interpretación de las cifras. La diferencia entre el avalúo de los bienes y el ingreso del mismo por remates es otro de los datos confusos, pues generalmente no se presentaban con claridad estas cuentas; sin embargo, hasta el año 1869 se contaban ganancias por ventas de $\$ 7.032,215,75$; si tomamos la anterior cifra como valor acumulativo desde el momento de la desamortización, es decir, 1861, no se explicaría la razón por la cual en el año 1866 se mostró un ingreso al ramo por ventas de \$7.566.202,50. 
GRÁFICO 4: INVENTARIO GENERAL DEL RAMO DE BIENES DESAMORTIZADOS, 1869-1871

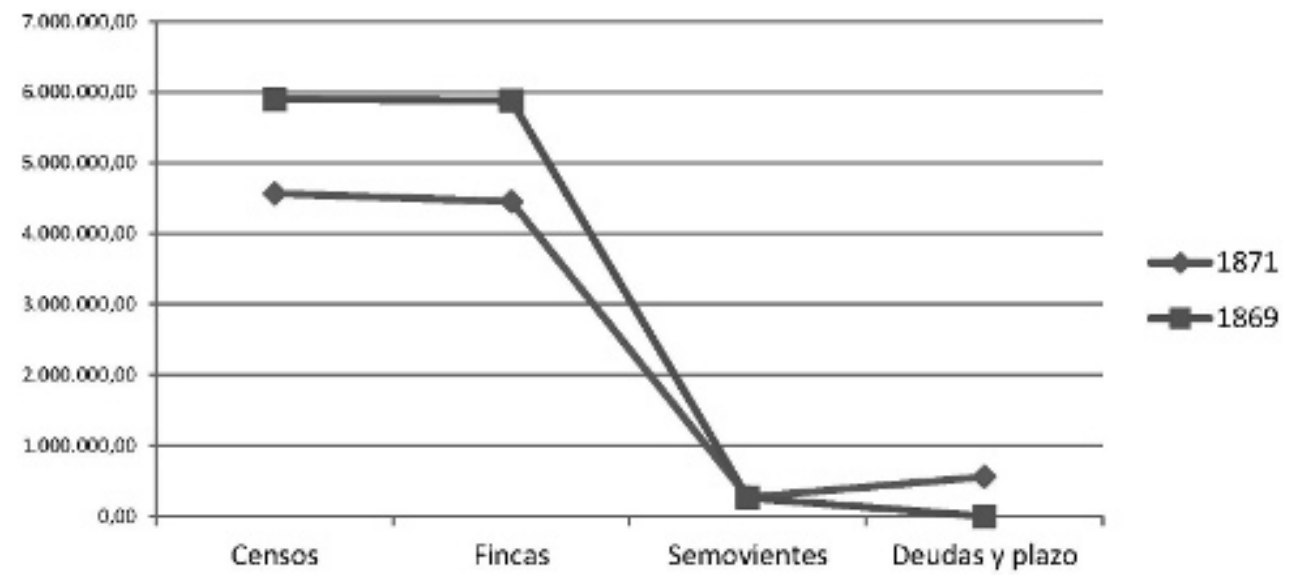

Fuente. Informe del Agente General de bienes desamortizados, 1868; 1872. Elaboracion de la autora.

La participación de cada Estado en la aplicación efectiva sobre los bienes de manos muertas se vio reflejada en la suma total que cada uno de ellos aportó al ramo de bienes desamortizados, de tal manera que podemos deducir que la ciudad de Bogotá, capital de la Unión, reflejó un proceso de trasformación de la tierra y de los bienes; asimismo, se destaca el surgimiento de una clase de nuevos propietarios, muchos de ellos inversionistas, quienes adquirían tierras como un bien de capital, las cuales arrendaban o remataban posteriormente; muy pocos se dedicaron directamente a la agricultura.

En el Estado del Magdalena, según las cifras de inscripción y remate, se evidenció poca rotación de la tierra y bienes ${ }^{75}$. En términos generales, se mantuvo al margen de la reforma en un $99,4 \%$.

Desde el punto de vista porcentual, este Estado participó con un 0,06\% del total de los bienes inscritos y rematados, siguiendo en su orden: Santander (5\%), Bolívar (6\%), Antioquia y Tolima (7\%), Panamá y Cauca (8\%), Boyacá $(11 \%)$ y Cundinamarca-Bogotá con el $47 \%{ }^{76}$, siendo Bogotá la entidad territorial que aportó el mayor número de bienes inscritos y rematados. Los

\footnotetext{
75 De La Cruz-Vergara, 2014b: 49-54.

76 Los porcentajes se dedujeron de las cifras consolidadas en 1872 por el Agente General Miguel Gutiérrez.
} 


\section{GRÁFICO 5: REPRESENTACIÓN DE LA TRASFORMACIÓN DE LA PROPIEDAD EN CADA ESTADO}

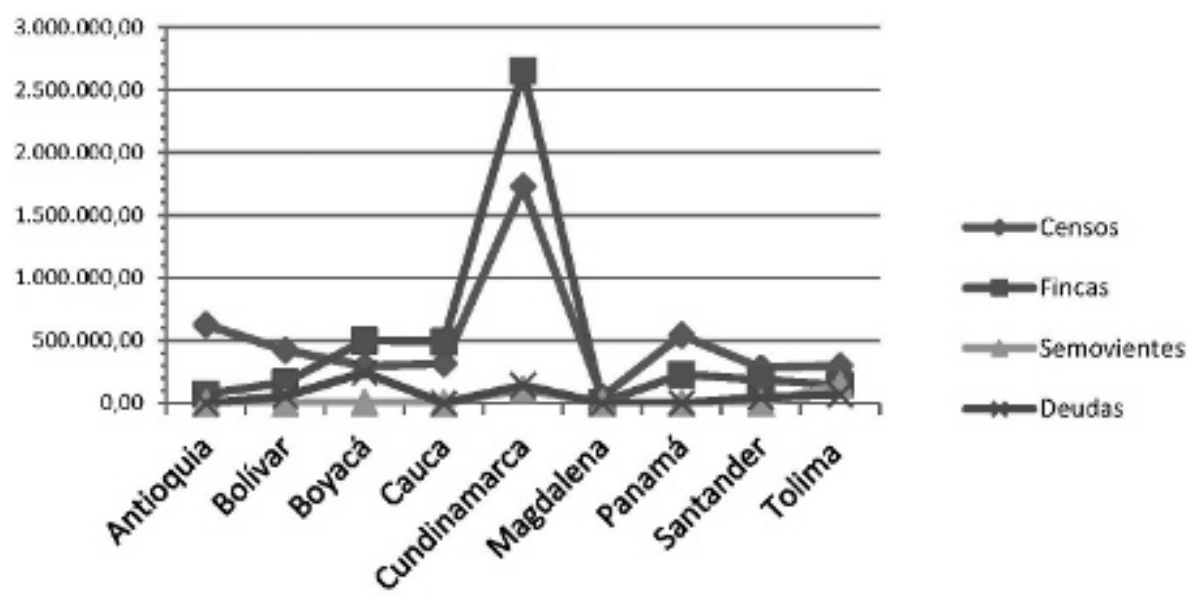

Fuente: Informe del Agente General de bienes desamortizados, 1866; 1868; 1875; 1877. Agencia General de bienes desamortizados, 1869. Memoria del Secretario del Tesoro y Crédito Nacional al Congreso, 1870; 1871; 1874. Memoria dirigida al ciudadano presidente..., 1872. Memoria presentada al presidente de los Estados Unidos..., 1873. Nueva rectificación de hechos sobre la cuestión remates, 1867. Elaboración de la autora.

remates reportados se ubicaban especialmente en las capitales de los Estados o en las ciudades de provincias o pueblos más grandes.

Los bienes ubicados en zonas rurales fueron más difíciles de incluir, de lo cual se desprende que mientras en las ciudades se inició un proceso de aceleración, de ruptura con las antiguas estructuras de propiedad sobre la tierra y los bienes, las zonas rurales quedaban intactas o a media marcha; en consecuencia, y en estricto sentido, se debe hablar de una reforma urbana de la propiedad, que sirvió de base para dar inicio al proceso de modernización de las ciudades y de nuevas formas de apropiación de la tierra en la primera mitad del siglo XX.

Para finalizar, se debe decir que la desamortización logró legitimar, en la práctica, el concepto de propiedad privada individual sobre la tierra y bienes, pero, además, involucró aspectos políticos de partidos y de clases, lo que condujo no solamente a conflictos sociales, sino a un estado de guerra propiciado por un pensamiento reformador y un pensamiento de estatus de propiedad establecido desde tiempo atrás y que estaba lejos de la lógica capitalista; en todo caso, la Regeneración se presentó como la alternativa para salir del caos político en que se hallaba el país y que desembocó en la Constitución 
de 1886, la cual, en el título II, artículo 31, hizo referencia a que a nadie se le desconocieran sus derechos sobre los títulos de propiedad que había adquirido legítimamente.

\section{CONCLUSIONES}

Esta reforma se caracterizó por ser de carácter nacional y urbana, tanto en sus políticas como en la estrategia administrativa que se utilizó para captar los recursos y bienes. Las cuentas, como se dijo anteriormente, estaban centralizadas en una contabilidad general y era la Hacienda Pública, con sede en la capital de la Unión, la que se encargaba de auditar y determinar sobre el asunto, no obstante la autonomía de los agentes principales. En esta red política-administrativa y contable, los Estados Soberanos eran determinantes en la medida en que del dinamismo que le imprimieran a la reforma dependía la trasformación de la propiedad sobre la tierra y de los bienes en cada uno de ellos. Fue así como Bogotá mostró altos porcentajes de dicha trasformación, mientras el Estado del Magdalena prácticamente, de acuerdo con lo recaudado, se mantuvo al margen de la misma.

De otra parte, si bien es cierto que fue una reforma sobre la propiedad, también lo es que no puede considerarse una reforma social amplia, pues los nuevos propietarios debían contar con dinero o bonos de la deuda para poder ofertar por los bienes ${ }^{77}$, de tal manera que se desarticuló la propiedad comunal y los bienes corporativos para entrar totalmente en la era de la propiedad individual, en donde la concentración de la tierra y de bienes quedaría en pocas manos. Es decir, se desarticuló un sistema de propiedad en donde el concepto de igualdad no existía, y se pasó a un sistema de propiedad individual, cuyo concepto de igualdad era posible solo a través de la ley o de las oportunidades que cada individuo se procurara, lo que conduce a pensar que las reformas no modificaron sustancialmente la sociedad y que éstas se debatían básicamente entre las luchas partidistas, las reformas administrativas y la organización territorial en función del proyecto político liberal en donde, como lo planteó Mosquera en su Testamento político, se habían cometido excesos por parte de ambos partidos, por lo que propuso que para lograr la paz y el bienestar social, los liberales y conservadores no radicales debían

77 En este punto la desamortización se alejó de la política de distribución de baldíos, ya que estos se utilizaron para motivar la inmigración extranjera, para la expansión de las fronteras agrícolas y la repartición de pequeñas parcelas a grupos de campesinos. 
alternarse en el poder ${ }^{78}$, siendo los más populares quienes más realizaran obras de infraestructura para el desarrollo del país.

\section{BIBLIOGRAFÍA Y FUENTES IMPRESAS}

Agencia General de bienes desamortizados, 1869, Bogotá, Imprenta de Gaitán, 1869, Biblioteca Luis Ángel Arango (BLAA).

Constitución y leyes de los Estados Unidos de Colombia, expedidas en los años de 1863 a 1875, T II, Bogotá, Imprenta de Medardo Rivas, 1875, Biblioteca Nacional de Colombia (BNC).

De La Cruz-Vergara, Maribel, "El proceso jurídico político de la desamortización de bienes de manos muertas en Colombia. 1766- 1886", El Taller de la Historia, I/1 (Cartagena, 2011): 203- 222.

De la Cruz-Vergara, Maribel, El proceso de liberalización de tierras en Colombia en el siglo XIX, tesis doctoral, Sevilla, Universidad Pablo de Olavide, 2012.

De La Cruz-Vergara, Maribel, "Remates y ventas de bienes desamortizados en Colombia. El caso del estado Soberano de Bolívar, 1861-1875", América Latina en la Historia Económica, 1 (México, enero-abril 2014a): 31-65.

De La Cruz-Vergara, Maribel, "Participación del Estado Soberano del Magdalena en las cuentas del ramo de Bienes Desamortizados. 1861-1875", Revista Arte y Diseño, 12/1 (Barranquilla, 2014b): 49-54.

Decreto reglamentando la administración de los bienes desamortizados, Bogotá, Imprenta de la Nación, 1864, BLAA.

Díaz Díaz, Fernando, La desamortización de bienes eclesiásticos en Boyacá, Tunja, Imprenta Universidad Pedagógica y Tecnológica de Tunja, 1977.

Díaz Díaz, Fernando, "Estado, Iglesia y desamortización", Jaime Jaramillo Uribe (dir.), Nueva historia de Colombia, Bogotá, Planeta, 1989: 411-466.

Estadística del comercio exterior y de cabotaje y de los demás ramos relacionados con la Hacienda nacional, correspondiente al año de 1870-1871, Bogotá, Imprenta de Gaitán, 1872, BNC.

Galindo, Aníbal, Historia económica y estadística de la hacienda nacional, desde la colonia hasta nuestros días, Bogotá, Imprenta de Nicolás Pontón y Compañía, 1874.

González, Florentino, Informe presentado por el Secretario de Estado del despacho de Hacienda, del gobierno de la Nueva Granada, Bogotá, Imprenta de J. A. Cualla, 1847.

78 Mosquera, 1867: 1-8. 
Informe del Agente General de bienes desamortizados, 1865, Bogotá, Imprenta de El Mosaico, 1866, BLAA.

Informe del Agente General de bienes desamortizados, 1866, Bogotá, Imprenta de Gaitán, 1867, BLAA.

Informe del Agente General de bienes desamortizados, 1867, Bogotá, Imprenta de Gaitán, 1868, BLAA.

Informe del Agente General de bienes desamortizados, 1870, Bogotá, Imprenta de Gaitán, 1871, BLAA.

Informe del Agente General de bienes desamortizados, 1871, Bogotá, Imprenta de Gaitán, 1872, BLAA.

Informe del Agente General de bienes desamortizados, 1873, Bogotá, s/n, 1874, BLAA, BNC, Fondo Pineda.

Informe del Agente General de bienes desamortizados, 1874, Bogotá, Imprenta de Echeverría Hermanos, 1875, BLAA.

Informe del Agente General de bienes desamortizados, 1875, Bogotá, Imprenta de Echavarría Hermanos, 1876, BLAA.

Informe del Agente General de bienes desamortizados, 1876, Bogotá, Imprenta de Gaitán, 1877, BLAA, miscelánea 1445.

Jaramillo, Roberto Luis y Méisel Roca, Adolfo, "Más allá de la retórica de la reacción, análisis económico de la desamortización en Colombia, 1861-1888”, Adolfo Méisel Roca y María Teresa Ramírez (eds.), Economía Colombiana del siglo XIX, Bogotá, FCE, Banco de la República de Colombia, 2010: 283-330.

Leyes y decretos expedidos por el Congreso Constitucional de la Nueva Granada, en el año de 1853, Bogotá, Imprenta del Neogranadino, 1854, BLAA.

Méisel Roca, Adolfo y Salazar Mejía, Irene, "La desamortización en el Caribe colombiano: una reforma urbana liberal 1861-1881", Historia Caribe, Revista de la Universidad del Atlántico, VII (Barranquilla, enero-junio de 2012): 119-146.

Memoria del Secretario del Tesoro y Crédito Nacional al Congreso de 1870, Colombia, Imprenta de Medardo Rivas, 1870, BLAA.

Memoria del Secretario del Tesoro y Crédito Nacional al Congreso de 1871, Bogotá, Imprenta de la Nación, 1871, BLAA.

Memoria del Secretario del Tesoro y Crédito Nacional dirigida al presidente de la Unión, para el Congreso de 1874, Bogotá, Imprenta de Gaitán, 1874, BLAA.

Memoria del Secretario del Tesoro y Crédito Nacional dirigida al presidente de la Unión, para el Congreso de 1875, Bogotá, Imprenta de Gaitán, 1875, BLAA. 
Memoria dirigida al ciudadano presidente de los Estados Unidos de Colombia, para presentarla al Congreso Federal, en sus sesiones ordinarias de 1872, Bogotá, Imprenta de Medardo Rivas, 1872, BLAA.

Memoria presentada al presidente de los Estados Unidos de Colombia por el Secretario del Tesoro y Crédito Nacional, 1873, Bogotá, Imprenta de Gaitán, 1873, BLAA.

Nueva rectificación de hechos sobre la cuestión remates, 1866, Bogotá, 1867, BLAA, Colombia.

Mosquera, T. C., Testamento Político del Gran General Tomás Cipriano de Mosquera, Bogotá, Imprenta de Echavarría Hermanos, 1867.

Observaciones sobre algunas leyes de la República, Bogotá, Imprenta de F. Torres Amaya, 1855, BLAA.

Recopilación de las disposiciones fundamentales y reglamentarias sobre crédito nacional y desamortización de bienes de manos muertas, decreto de 9 de septiembre de 1861, Bogotá, Imprenta de la Nación, 1862, BLAA.

Rico Bonilla, Orlando, "Confiscación de bienes eclesiásticos en Colombia. La contabilidad de la Agencia General de bienes desamortizados (1861-1888)", De Computis, Revista Española de Historia de la Contabilidad, 12 (Revista en línea, junio 2010): 41-83, http://decomputis.org/ojs/index.php/decomputis/article/view/277, fecha de consulta: abril de 2014.

Fecha de recepción: 1 de noviembre de 2014.

Envía modificaciones: 4 de mayo de 2015 y 25 de agosto de 2015.

Fecha de aceptación: 26 de agosto de 2015.

\section{Participation of sovereign states in the general trade of disentailed properties in the second half of nineteenth-century Colombia}

The objective of this research revolves around the quantitative analysis of the participation of Sovereign States in the general trade of disentailed properties in the second half of nineteenth-century Colombia, through the interpretation of reports by public stewards of disentailed properties and the data reported in public financial papers.

Key wORDS: Colombia; disentailment; Sovereign States; properties; auctions. 